Tropical Journal of Pharmaceutical Research, April 2009; 8 (2): 111-116

(C) Pharmacotherapy Group,

Faculty of Pharmacy, University of Benin,

Benin City, 300001 Nigeria.

All rights reserved.

Research Article

Available online at http://www.tjpr.org

\title{
Dose-Dependent Amelioration of Gentamicin-Induced Nephrotoxicity in Adult Swiss Albino Rats by Vitamin B-complex - A Preliminary Study
}

\section{Shaibu O Bello ${ }^{1,2^{\star}}$ and Aminu Chika ${ }^{1}$}

${ }^{1}$ Department of Pharmacology, College of Health Sciences, Usmanu Danfodiyo University, ${ }^{2}$ Fertility Unit, Karaye Hospital, Emir Yahaya Road, Sokoto, Nigeria.

\begin{abstract}
Purpose: To evaluate the effect of vitamin B-complex on the nephrotoxicity of gentamicin in an established rat model.

Methods: Adult Swiss albino rats weighing 170 $\pm 20 \mathrm{~g}$ were divided into 4 groups of 4 rats each. Each group was given one of the following: placebo injection (Control), $80 \mathrm{mg} / \mathrm{kg}$ of gentamicin sulphate alone or with $1.5 \mathrm{ml} / \mathrm{kg} / 3 \mathrm{ml} / \mathrm{kg}$ body weight of vitamin $B$-complex (intramuscular) containing $10 \mathrm{mg}$ thiamine, $1.5 \mathrm{mg}$ riboflavin and $1.0 \mathrm{mg}$ pyridoxal-6-phosphate per $\mathrm{ml}$.

Results: In the Swiss albino rats, daily intramuscular $80 \mathrm{mg} / \mathrm{kg}$ gentamicin sulphate significantly $(p<0.05)$ and consistently produced biochemical signs of nephrotoxicity after 5 days. Also, $1.5 \mathrm{ml} / \mathrm{kg}$ of $B$-complex significantly $(p<0.05)$ ameliorated the rate and extent of increase in serum urea and creatine while $3 \mathrm{ml} / \mathrm{kg}$ of the same drug completely prevented the increase in serum urea and creatine in this model.

Conclusion: Vitamin B-complex dose-dependently ameliorated gentamicin-induced nephrotoxicity in adult Swiss albino rats when given intramuscularly. This finding may have important clinical utility.
\end{abstract}

Keywords: Gentamicin, B-complex, Swiss albino rats, Nephrotoxicity, Serum urea and creatine. 


\section{Introduction}

Gentamicin is a bactericidal antibiotic with wide clinical use but disturbing toxicity. Nephrotoxicity and ototoxicity are the most common adverse reactions ${ }^{1,2}$. While nephrotoxicity is almost always reversible due to the regenerating ability of the proximal renal tubules $^{1}$, gentamicin still contributes to an increased incidence of the rather permanent ototoxicity $^{2}$. Various attempts at controlling gentamicin toxicity have been frustrated by lack of a clear understanding of the mechanism of toxicity. Nephrotoxicity has been related to a gentamycin trough concentration above $2 \mu \mathrm{g} / \mathrm{ml}$, calcium deficiency, calcium channel activation, prostaglandins pathways, free radical generation, pyridoxal phosphate deficiency and ascorbic acid depletion ${ }^{1}$. Once daily and extended interval dosing were designed to optimize the concentration-dependent antibiotic activity and essentially timedependent toxicity of gentamicin but the rather wide difference in serum concentrations and the fact that these dosing modes have not been substantiated in pregnancy, paediatric age group and endocarditis, indicate that there are still limitations using these approaches ${ }^{3}$. Though a recent study suggests some usefulness of the approach in neonates, trough levels were still above $2 \mu \mathrm{g} / \mathrm{ml}$ even at $q 48$ hours dosing ${ }^{4}$. Other attempts at controlling gentamicin toxicity, including the use of pyridoxal phosphate, ascorbic acid, calcium loading, calcium channel blocker, ${ }^{1}$ vitamin $\mathrm{E}^{5}$ and acupuncture ${ }^{6}$ have shown either promising or inconsistent results in animals. Those that showed limited efficacy have been difficult to apply clinically due to caution in administering agents that could be toxic themselves or require dose schedules that are not practical in patients ${ }^{1}$. Hence, an agent that is known to be clinically safe and effective as formulated would be easier to use clinically if found to be effective in ameliorating gentamicin toxicity. Vitamin B-complex could be such an agent.
Vitamin B-complex is a well known preformulated combination of water-soluble $\mathrm{B} 1$ (thiamine), B2 (riboflavin) and B6 (pyridoxal) with or without nicotinamide and ascorbic acid. Depletion of some of these ingredients has been suggested to contribute to gentamicin toxicity ${ }^{7,8,9}$. This study was carried out as a preliminary evaluation of the influence of B-complex, administered intramuscularly, on the nephrotoxicity of gentamicin.

\section{Experimental}

Adult, female, Swiss albino rats, weighing $170 \pm 20 \mathrm{~g}$, were obtained from the breeding unit of the Veterinary Research Institute, Vom, Nigeria, and randomly distributed into 4 groups of 4 rats each. The rats were housed in groups at a room temperature of $23 \pm 3^{\circ} \mathrm{C}$ and relative humidity of $53-60 \%, 12$ hours light and 12 hours darkness cycles, fed ad libitum on water and standard chow, and acclimatized for 14 days before experimentation. The groups were randomly scheduled to receive the following: Group 1: $0.9 \%$ saline (placebo) intramuscularly (i.m.) daily for 10 days; Group 2: gentamicin only $80 \mathrm{mg} / \mathrm{kg}$ body weight/day i.m. for 10days; Group 3: gentamicin $80 \mathrm{mg} / \mathrm{kg}$ body weight /day i.m. plus $1.5 \mathrm{ml} / \mathrm{kg}$ body weight of vitamin B-complex daily for 10 days; and Group 4: gentamicin $80 \mathrm{mg} / \mathrm{kg}$ body weight /day i.m. plus $3 \mathrm{ml} / \mathrm{kg}$ of vitamin Bcomplex daily for 10 days . B-complex (JINLIN-Pharmacy China, with National Agency for Food and Drug Administration and Control [NAFDAC] registration no. 04-7068) containing $10 \mathrm{mg}, 1.5 \mathrm{mg}$ and $1.0 \mathrm{mg}$ of $\mathrm{B} 1$, $\mathrm{B} 2$ and B6, respectively, per $\mathrm{ml}$, and gentamicin sulphate injection (Gentalek ${ }^{\circledR}$, Lek Pharmaceutical and Chemical Company, Veroskova, Slovenia with NAFDAC no. 040220) were used for the study. The dose of gentamicin used has been consistently demonstrated to induce nephrotoxicity in adult rats $^{10}$ while the dose of B-complex used was the pharmacological equivalent (in rats) of the usual clinical dose in $\operatorname{man}^{11}$. The animals were weighed every alternate day and the last 
known weight was used for dose calculations. Blood samples were collected by tail bleeding at day zero (day 1 being the day treatment was started) and the other blood samples were collected by cardiac puncture 24 hours after the last administration. Each sample was collected in a sterile sample bottle without anticoagulant and the serum was removed for analysis. Serum creatine and urea were quantified using reagent kits from BioAnalytics Company (Palm City, U.S.A.). The data obtained were analyzed using Microsoft Excel $^{\circledR}$ add-on, Analyze-it ${ }^{\circledR}$, and SATS ${ }^{\circledR}$ software. Student's t-test was used for within group comparison while one-way ANOVA with Bonferroni error correction was used for between groups comparison. The animal experiment was carried out in accordance with the National Institutes of Health guidelines and was approved by the Animal Ethical Committee of the College of Health Sciences, Usmanu Danfodiyo University, Sokoto.

\section{Results}

In Swiss albino rats, daily doses of gentamicin, $80 \mathrm{mg}$ i.m., significantly $(p<0.05)$ and progressively increased serum creatine $(1.33 \pm 0.22,3.38 \pm 0.22$, and $4.78 \pm 0.46 \mathrm{mmol} / \mathrm{l}$ at days 0,5 and 10 , respectively) and serum urea $(6.95 \pm 2.07,18.28 \pm 1.01$, and $42.18 \pm 1.18$ $\mathrm{mg} / \mathrm{dl}$ at days 0,5 and 10 , respectively) during the study when compared to placebo-treated animals (control) that revealed no significant difference in these parameters (Table 1). Also, $1.5 \mathrm{ml} / \mathrm{kg}$ body weight of vitamin B-complex significantly $(p<0.05)$ ameliorated the rate and extent of increase in serum creatine and urea while $3 \mathrm{ml} / \mathrm{kg}$ body weight of vitamin Bcomplex completely prevented an increase in serum urea and creatine throughout the duration of the study (Figures 1 and 2). There was a slight but insignificant ( $p>0.05)$ reduction in body weight in all groups by day 5 of the experiment as shown in Table 1.

\section{Discussion}

This study shows that $80 \mathrm{mg} / \mathrm{kg}$ body weight/day of gentamicin sulphate (i.m.) consistently produced nephrotoxicity as reflected by the progressive increase in serum urea and creatine. These consistent effects have been recognized ${ }^{5,6,7}$ and suggest that histological studies of the kidney may not be necessary to confirm nephrotoxicity in this model $^{6}$. The dose-dependent amelioration of nephrotoxicity in this model by vitamin Bcomplex is clinically important. If explored at a molecular level, it may elicit additional information on the mechanism of gentamicin toxicity. Vitamin B-complex is commonly used clinical therapy but studies in humans are necessary to confirm findings from this work before clinical use of the approach used in our study is adopted. It is expected to be safer than the use of a calcium channel blocker or calcium loading. Though complete inhibition of gentamicin toxicity at $3 \mathrm{ml} / \mathrm{kg}$ body weight/day was way beyond the preliminary hypothesis for this study, amelioration was expected because previous studies have shown significant amelioration of toxicity by prydoxal6-phosphate (B6) and free radical moppers ${ }^{1}$. It is interesting to note that the amount of vitamin B-complex given to animals in this study (1.5 and $3 \mathrm{ml}$ of B-complex) translates to a pyridoxal-6-phosphate dose range of 1.5 to $3 \mathrm{mg} / \mathrm{kg} / \mathrm{body}$ weight while previous studies have shown pyridoxal-6-phosphate to reduce, but not prevent, gentamicin nephrotoxicity at doses above $10 \mathrm{mg} / \mathrm{kg}$ body weight (usually $100 \mathrm{mg} / \mathrm{kg}$ body weight) ${ }^{12,13}$. These studies also found doses below $10 \mathrm{mg} / \mathrm{kg}$ to be ineffective ${ }^{12,13}$. The efficacy of the much lower doses used in this study may suggest synergism with some other components of vitamin B-complex. The mechanism of the apparent synergism will need to be explored.

One drawback to this study is that vitamin Bcomplex is not a uniform combination formulation. Though all formulations usually contain B1, B2 and B6, the quantity and ratios are often different. Furthermore, some also contain nicotinamide and ascorbic acid. These may influence the effect on gentamicin nephrotoxicity either positively or negatively. However, given that these are free radical moppers, the expectation is that there could be synergism in ameliorating nephrotoxicity. 
Table 1: Body weight, and serum urea and creatine values of albino rats

\begin{tabular}{|c|c|c|c|c|c|c|c|c|c|}
\hline \multirow{2}{*}{$\begin{array}{l}\text { Parameter } \\
\text { Group }\end{array}$} & \multicolumn{3}{|c|}{ Body Weight (g) } & \multicolumn{3}{|c|}{ Serum Urea (mmol/l) } & \multicolumn{2}{|c|}{ Serum Creatine } & \multirow{2}{*}{$\begin{array}{l}(m g / d l) \\
\text { Day } 10\end{array}$} \\
\hline & Day 0 & Day 5 & Day 10 & Day 0 & Day 5 & Day 10 & Day 0 & Day 5 & \\
\hline Control & $\begin{array}{r}194.05 \\
\pm 15.76\end{array}$ & $\begin{array}{l}182.70 \\
\pm 6.91\end{array}$ & $\begin{array}{r}193.15 \\
\pm 18.53\end{array}$ & $\begin{array}{l}1.30 \\
\pm 0.14\end{array}$ & $\begin{array}{l}1 . .35 \\
\pm 0.40\end{array}$ & $\begin{array}{l}1.28 \\
\pm 0.46\end{array}$ & $\begin{array}{l}6.80 \\
\pm 0.81\end{array}$ & $\begin{array}{l}6.91 \\
\pm 1.05\end{array}$ & $\begin{array}{l}7.20 \\
\pm 2.45\end{array}$ \\
\hline $\begin{array}{l}\text { Gentamicin } \\
\text { alone }\end{array}$ & $\begin{array}{l}166.03 \\
\pm 22.21\end{array}$ & $\begin{array}{l}163.90 \\
\pm 26.91\end{array}$ & $\begin{array}{l}178.95 \\
\pm 32.72\end{array}$ & $\begin{array}{l}1.33 \\
\pm 0.22\end{array}$ & $\begin{array}{l}{ }^{*} 3.38 \\
\pm 0.22\end{array}$ & $\begin{array}{l}{ }^{*} 4.78 \\
\pm 0.46\end{array}$ & $\begin{array}{l}6.95 \\
\pm 2.07\end{array}$ & $\begin{array}{l}{ }^{*} 18.28 \\
\pm 1.01\end{array}$ & $\begin{array}{l}{ }^{*} 42.18 \\
\pm 1.18\end{array}$ \\
\hline $\begin{array}{l}\text { Gentamicin } \\
+1.5 \mathrm{mlBCo}\end{array}$ & $\begin{array}{l}169.58 \\
\pm 7.73\end{array}$ & $\begin{array}{l}164.58 \\
\pm 26.91\end{array}$ & $\begin{array}{l}166.28 \\
\pm 8.99\end{array}$ & $\begin{array}{l}1.23 \\
\pm 0.26\end{array}$ & $\begin{array}{l}* 1.79 \\
\pm 0.22\end{array}$ & $\begin{array}{l}* 2.18 \\
\pm 0.77\end{array}$ & $\begin{array}{l}6.78 \\
\pm 1.15\end{array}$ & $\begin{array}{l}{ }^{*} 10.08 \\
\pm 0.74\end{array}$ & $\begin{array}{l}{ }^{*} 18.13 \\
\pm 1.20\end{array}$ \\
\hline $\begin{array}{l}\text { Gentamicin } \\
+3 \mathrm{ml} \mathrm{BCo}\end{array}$ & $\begin{array}{l}163.15 \\
\pm 25.29\end{array}$ & $\begin{array}{r}161.98 \\
\pm 29.71\end{array}$ & $\begin{array}{l}156.18 \\
\pm 30.34\end{array}$ & $\begin{array}{l}1.29 \\
\pm 0.26\end{array}$ & $\begin{array}{l}1.45 \\
\pm 0.17\end{array}$ & $\begin{array}{l}1.35 \\
\pm 0.16\end{array}$ & $\begin{array}{l}6.55 \\
\pm 1.72\end{array}$ & $\begin{array}{l}6.98 \\
\pm 1.23\end{array}$ & $\begin{array}{l}6.53 \\
\pm 1.58\end{array}$ \\
\hline
\end{tabular}

All values are mean of 4 values \pm standard deviation.

* Significantly $(P<0.05)$ different from the preceding reading within its group, using $t$-test, and from all readings in the control group using one-way ANOVA with Bonferroni error control.

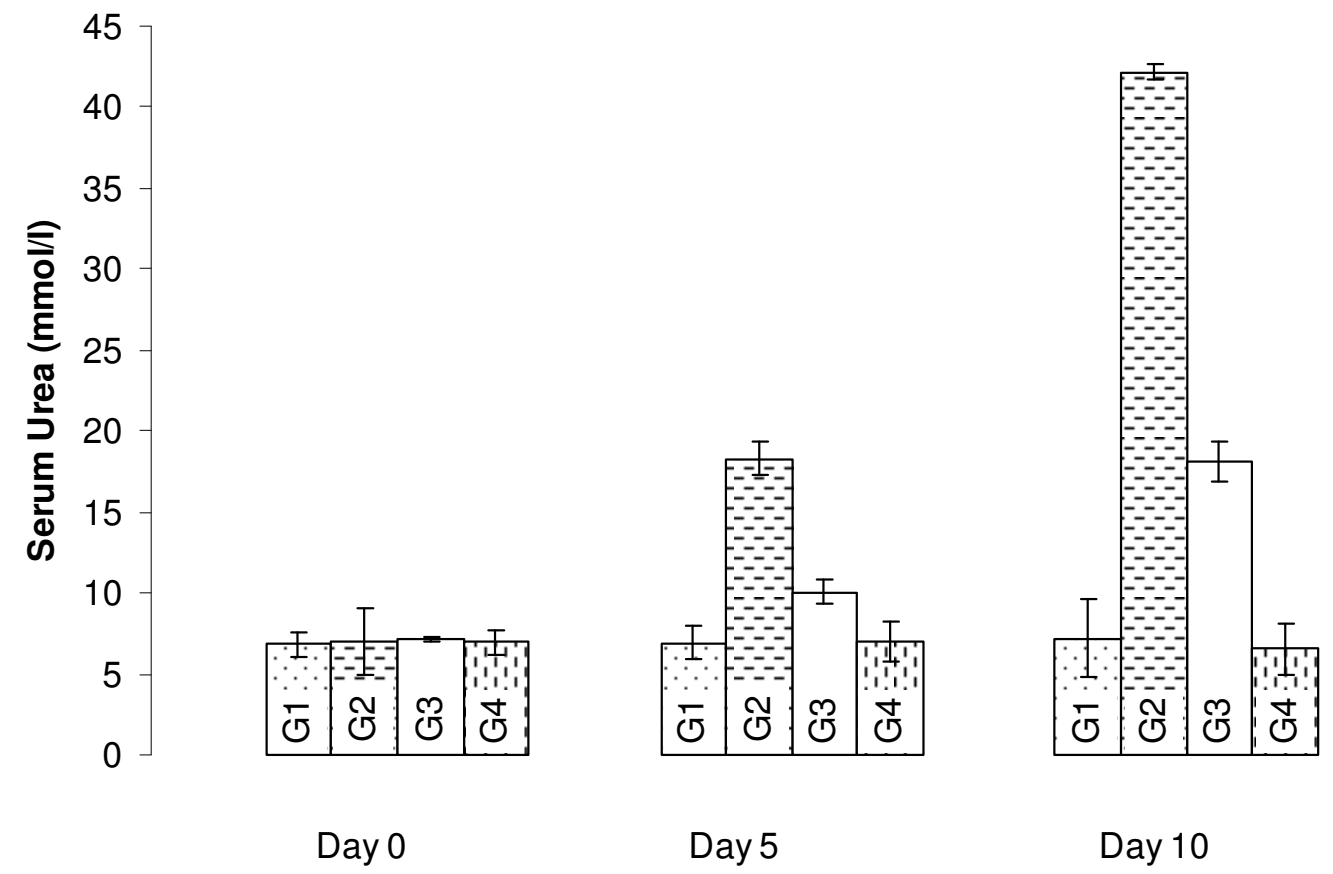

Figure 1: Amelioration of the increase in serum urea by vitamin B-complex injection.

G1: Control. G2: Gentamicin 80mg i.m daily for 10 days. G3: gentamicin $80 \mathrm{mg}$ i.m daily for 10 days plus $B$-complex , $1.5 \mathrm{ml}$ daily for 10 days. G4: gentamicin $80 \mathrm{mg}$ i.m. daily for 10 days plus B-complex , 3ml daily for 10days.

B-Complex: Vitamin B-complex containing 100mg, 15mg and 10mg of B1, B2 and B6 respectively per 10 $\mathrm{ml}$ ampoule. 


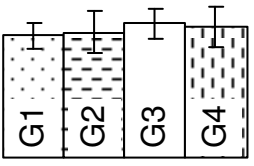

Day 0

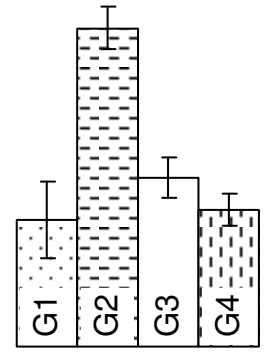

Day 5

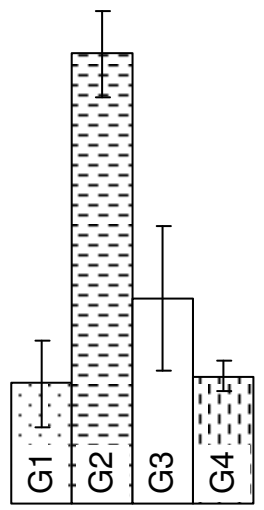

Day 10

Figure 2: Amelioration of increase in serum creatine by intramuscular vitamin B-complex

G1: Control. G2: Gentamicin 80mg i.m daily for 10 days. G3: gentamicin $80 \mathrm{mg}$ i.m daily for 10 days plus $B$-complex , $1.5 \mathrm{ml}$ daily for 10 days. G4: gentamicin $80 \mathrm{mg}$ i.m. daily for 10 days plus $B$-complex, $3 \mathrm{ml}$ daily for 10days; B-Complex: Vitamin B-complex containing 100mg, $15 \mathrm{mg}$ and $10 \mathrm{mg}$ of B1, B2 and B6 respectively per $10 \mathrm{ml}$ ampoule.

The pharmaceutical, pharmacokinetic and pharmocodynamic interactions of B-complex with gentamicin may also need to be defined. The B-complex used in this study and the quantity of its components was chosen at random. It best serves as a baseline for further exploration.

\section{Conclusion}

Gentamicin nephrotoxicity may be ameliorated or prevented by vitamin B-complex. This finding is clinically important but needs to be explored further to determine the optimum dose and combinations of the B-vitamins.

\section{References}

1. Martínez-Salgado C, López-Hernández FJ, LópezNovoa JM. Glomerular nephrotoxicity of aminoglycosides. Toxicol Appl Pharmacol 2007; 223(1): 86-98
2. Rybak LP, Ramkumar V. Ototoxicity. Kidney Int. 2007; 72(8): 931-5.

3. Gilbert DN. Mini-Review: Once daily aminoglycoside therapy. Antimicrob Agents Chemotherapy. 1991; 35: 399-405

4. Darmstadt GL, Hossain MM, Jana AK, Saha SK, Choi $Y$, Sridhar $S$ et al. Determination of extendedinterval gentamicin dosing for neonatal patients in developing countries. Pediatr Infect Dis J. 2007; 26(6): 501-507

5. Varzi HN, Esmailzadeh $S$, Morovvati $H$, Avizeh $R$, Shahriari A, Givi ME. Effect of silymarin and vitamin $E$ on gentamicin-induced nephrotoxicity in dogs. J Vet Pharmacol Ther. 2007; 30(5): 477-481.

6. Ma WJ, Xu M, Zhang XT, Liu H, Li HY, Zhou XH. Observation on acupuncture at "Neitinggong" for antagonisting ototoxicity caused by gentamicin. Zhongguo Zhen Jiu. 2007; 27(3): 209-212

7. Weir MR, Keniston RC, Enriquez JI Sr, McNamee GA. Depression of vitamin B6 levels due to gentamicin. Vet Hum Toxicol. 1990; 32(3): 235238

8. Ohtani I, Ishida H, Mizuno S, Ouchi J. Experimental study on the effect of thiamine derivative upon the kanamycin ototoxicity. ORL J 
Otorhinolaryngol Relat Spec. 1974; 36(6): 344 354.

9. Pinto J, Raiczyk GB, Huang YP, Rivlin RS. New approaches to the possible prevention of side effects of chemotherapy by nutrition. Cancer. 1986; 58(8 Suppl):1911-1914

10. Soliman KM, Abdul-Hamid M, Othman Al. Effect of carnosine on gentamicin-induced nephrotoxicity. Med Sci Monit. 2007; 13(3): 73-83

11. Ghosh MN. Fundamentals of Experimental Pharmacology, $2^{\text {nd }}$ ed., Scientific Book Agency, Calcutta, 1984.
12. Enriquez Jl Sr, Schydlower M, O'Hair KC, Keniston $R C$, Nadjem MA, Delgado I. Effect of vitamin B6 supplementation on gentamicin nephrotoxicity in rabbits. Vet Hum Toxicol. 1992; 34(1):32-35

13. Keniston RC, Cabellon S Jr, Yarbrough KS. Pyridoxal 5'-phosphate as an antidote for cyanide, spermine, gentamicin, and dopamine toxicity: an in vivo rat study. Toxicol Appl Pharmacol. 1987; 88(3): 433-441 